\title{
Estrategias de apropiación territorial en un contexto de relación interétnica en Guamal, Caldas
}

Strategies of Territorial Appropriation in the Context
of Inter-ethnic Relations in Guamal, Caldas

DOI: $10.22380 / 2539472 X 5$

\section{Sofía Lara-Largo}

Universidad Paris VII Diderot, Unidad de Investigación sobre Migraciones y Sociedades (Urmis)

sophielara@gmail.com

\section{$\overline{\text { RESUMEN }}$}

En el artículo se abordan algunas estrategias de apropiación territorial en el contexto de las relaciones interétnicas de una localidad andina en Colombia. A través de ejemplos etnográficos y jurídicos se analizan las relaciones de poder que configuran las prácticas territoriales, en un contexto en el que las intervenciones de la política multicultural del Estado colombiano han influido en la producción de discursos sobre la etnicidad que son apropiados en diferentes niveles por los grupos locales. Este análisis busca revelar la complejidad de la puesta en escena de lo afro y lo indígena en una localidad como Guamal, e intenta escapar de las lecturas esencialistas o pragmatistas de la etnicidad, al hacer énfasis en las dinámicas político-territoriales que configuran las fronteras étnicas.

Palabras clave: apropiación territorial, poder, relaciones interétnicas, políticas multiculturales.

\section{ABSTRACT}

This paper discusses some strategies of territorial appropriation in the context of inter-ethnic relations in an Andean locality in Colombia. Through ethnographic and legal examples I analize power relations that shape territorial practices, in a context in which multicultural policy interventions of the Colombian state have influenced the production of ethnicity discourses that are appropriated at different levels by local groups. This analysis seeks to reveal the complexities involved in the staging of Afro and indigenous concepts in a locality such as Guamal, while trying to avoid essentialist or pragmatic views on ethnicity by emphasizing political and territorial dynamics that shape ethnic frontiers/boundaries.

Keywords: Territorial appropriation, power, inter-ethnic relations, multicultural politics. 


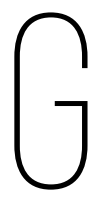

uamal ${ }^{1}$ se localiza en el municipio de Supía, en la región oriental del departamento de Caldas en Colombia. Cuenta con una serie de particularidades que la hacen especialmente significativa para el estudio de la apropiación territorial en un contexto de relación interétnica. En primer lugar, esta localidad se encuentra ubicada en una región que se ha caracterizado por una fuerte presencia de comunidades indígenas embera-chamíes. Actualmente la habita una importante población afrocolombiana que se reivindica como descendiente de los antiguos pobladores esclavizados del periodo colonial, además de otras poblaciones rurales y urbanas que no defienden ninguna particularidad étnica. Este conjunto de características permite suponer que Guamal es una localidad en la que se producen relaciones de carácter interétnico y en la que constantemente se ponen en juego las distintas aproximaciones de las comunidades sobre la relación entre la identidad y el territorio.

En segundo lugar, allí convergen diferentes tipos y niveles de administración territorial. Por una parte, Guamal es una vereda ${ }^{2}$ adscrita a la Administración del municipio de Supía y a la jurisdicción especial del resguardo indígena de Cañamomo y Lomaprieta ${ }^{3}$. Por otra parte, dado que Guamal es una localidad habitada por afrodescendientes, actualmente se encuentra conformado allí un consejo comunitario de comunidades negras, de acuerdo al marco normativo de la Ley 70 de 1993 que les atribuye a estas organizaciones una serie de derechos políticos y territoriales.

El presente texto toma fuerza de este panorama de fenómenos políticoterritoriales e identitarios y busca analizar, a través de dos viñetas etnográficas y jurídicas, algunas de las estrategias de apropiación territorial que se ponen en marcha en este contexto de relación interétnica. Estos ejemplos permitirán ver en qué medida algunas intervenciones estatales, sobre todo relacionadas con la

1 Los análisis y debates que se desarrollan en el presente artículo nacen de mi investigación doctoral "Les usages ethniques du territoire. Relations interethniques et appropriation territoriales à Guamal, Colombie”, en Antropología y Sociología de la Universidad París VII Diderot, bajo la dirección de Odile Hoffmann.

2 Unidad de subdivisión territorial que depende administrativa y políticamente de los entes municipales. En la mayoría de los casos, las veredas han servido para agrupar y organizar geográficamente las zonas rurales aledañas a los cascos urbanos o situadas en los caminos que comunican los centros más densamente poblados.

3 El resguardo de Cañamomo y Lomaprieta, de origen colonial, "se encuentra ubicado entre los municipios de Riosucio y Supía, con una extensión aproximada de 4.826 hectáreas distribuidas en 32 comunidades, 20 de las cuales se ubican en jurisdicción de Riosucio y las 12 restantes en Supía [...] Las autoridades de Cañamomo y Lomaprieta remontan la fundación de su resguardo a la cédula real expedida por Carlos I de España el 10 de marzo de 1540, mientras que otras fuentes sitúan en 1627 la creación de los resguardos de la zona, a raíz de la visita del oidor español Lesmes de Espinoza y Saravia” (Lopera-Mesa 2010, 68). 
Constitución Política de 1991, contribuyen a la reconfiguración y a la creación de prácticas y discursos relativos a la identidad étnica y a su relación con la apropiación territorial.

El texto se estructura en cuatro apartados. En el primero se propone presentar el anclaje del tema que nos ocupa en un panorama más amplio de estudios sobre las relaciones interétnicas en el contexto del multiculturalismo colombiano, así como algunas precisiones conceptuales a modo de introducción. En el segundo se plantea la primera de dos viñetas etnográficas y jurídicas. Esta alude a las confrontaciones que tuvieron lugar en el marco de la formalización del Consejo Comunitario Afrodescendiente de Guamal en el año 2013 . En este caso se hará énfasis en las estrategias de apropiación territorial de orden jurídico que se pusieron en marcha alrededor de dicha formalización. En el tercer apartado se hace referencia a una segunda viñeta, esta vez relacionada con los discursos y prácticas locales que emergen alrededor del testamento que dejara una antigua propietaria de esclavos a principios del siglo XIX. En este caso se insiste en la puesta en marcha de estrategias distintas a aquellas del orden jurídico; se destacarán entonces las estrategias mítico-religiosas, de acción política y del parentesco. En la última sección, dedicada a las conclusiones, se dejan abiertos nuevos interrogantes y reflexiones sobre contextos como el de esta localidad, en los que los límites de la identidad étnica no están predefinidos ni son necesariamente estáticos.

\section{Multiculturalismo y relaciones interétnicas, algunas precisiones conceptuales}

El presente análisis se enmarca en un contexto más amplio de estudios sobre las relaciones interétnicas en Colombia. Especialmente se inserta en el debate sobre los procesos de construcción de las fronteras identitarias en medio de disputas políticas y territoriales. Los estudios precedentes han aportado significativamente a la comprensión de los fenómenos de contacto interétnico o intercultural en regiones marcadas por una fuerte inestabilidad política, en donde las relaciones de poder están en constante reconfiguración, como las del Pacífico caucano,

\footnotetext{
4 El reconocimiento del Consejo Comunitario Afrodescendiente de Guamal por parte del Ministerio del Interior tuvo lugar a través de la Resolución n. 083 proferida el 10 de julio de 2013.
} 
nariñense y chocoano (Losonczy 1997; Otero 1994; Pacheco y Achito 1993; Rodríguez 2002a, 2002b, 2008; Ruiz 2006). A partir de este panorama investigativo, el estudio busca aportar nuevos elementos al debate desde otros terrenos. El contexto caldense podría dar nuevas pistas al estudio de la dimensión territorial de las relaciones interétnicas alrededor del fenómeno de la reivindicación de los derechos de las comunidades negras (Rodríguez 2008), que se ha dado en Caldas de manera tardía, en comparación con la región del Pacífico. Asimismo, el análisis de esta región del departamento de Caldas, reconocida por su diversidad cultural, contribuiría al debate sobre las búsquedas de la legitimidad y de la autoridad territorial emprendidas por los grupos étnicos en contextos en los que convergen múltiples actores en diferentes escalas, territoriales y políticas.

Al respecto, las relaciones de orden político y territorial que tienen lugar en la localidad de Guamal se insertan y convergen en un panorama más amplio de intervenciones estatales que han intentado reglamentar, sobre todo a partir de la aprobación de la Constitución Política de 1991, la diferencia y la diversidad cultural. Dichas intervenciones han influido en la manera en que las organizaciones sociales locales construyen un discurso basado especialmente en la identidad étnica, a través del cual se legitiman no solamente dentro de la misma comunidad, sino frente a comunidades vecinas y al mismo tiempo frente al Estado, con el fin de reclamar, entre otros, derechos políticos en el plano de lo territorial.

Cuando en este texto se habla de territorio, se hace referencia al principal productor, y al mismo tiempo principal resultado, de las relaciones de poder y de dominación en la búsqueda del control de un espacio determinado (Di Meo 1998; Raffestin 1980). Por su parte, el concepto de organizaciones sociales se relaciona específicamente con aquellos grupos de individuos que se movilizan por un objetivo común, y que en este caso reivindican diversos tipos de identidad e identificación fundamentados en la etnicidad, la diferenciación cultural, la búsqueda del poder, la autoridad y la legitimidad, en distintos niveles.

Las dinámicas de confrontación por los derechos políticos y territoriales que se presentan en esta localidad han sido afectadas por el contexto político regional y nacional más amplio, que ha influido en la consolidación de una serie de organizaciones sociales basadas en la identidad étnica afro. Cuando se habla del contexto político más amplio, se hace referencia especialmente a la aprobación, implementación y apropiación de una serie de normas que emergen en el marco de la Constitución multicultural. En este caso el Estado colombiano, a través de las diferentes formas de su institucionalidad, ha consolidado desde principios de la década de 1990 un discurso en el que se puede leer claramente su intención de definir, reglamentar y ajustar la diversidad cultural. En el caso 
específico de las comunidades negras en Colombia, la Ley 70 de 1993, que reglamentó el artículo transitorio 55 de la Constitución Política de 1991, es una de las mayores intervenciones del Estado en el reconocimiento de dichas comunidades, en lo concerniente a sus derechos tanto políticos como territoriales. Esta ley, en el momento de su firma, se consolidó como un instrumento fundamental de la lucha de múltiples organizaciones sociales en diferentes lugares del país, especialmente en el área geográfica delimitada por la cuenca del Pacífico, para reclamar derechos frente al Estado. Este fenómeno, a lo largo de las dos últimas décadas, ha llamado la atención de un importante número de académicos, quienes han mostrado un especial interés por analizar las características de la emergencia de este nuevo actor étnico y las complejas relaciones que las comunidades negras han establecido con el Estado en la búsqueda de su reconocimiento y legitimidad política y territorial (Agudelo 2004; Agudelo, Hoffmann y Rivas 1999; Arocha 2004; Barbary y Urrea 2004; Cunin 2004; Escobar 1997; Hoffmann 2004; Ng'weno 2013; Pardo 1996; Restrepo 2013).

Sin embargo, no se puede olvidar que estas dinámicas estatales fueron precedidas por distintos momentos de movilización social, y responden a un importante panorama de transformaciones vividas en el interior de las comunidades, en respuesta a diferentes situaciones de orden económico, social y político (Agudelo 2004; Agudelo, Hoffmann y Rivas 1999; Barbary y Urrea 2004; Cunin 2004; Pardo 1996). La influencia de los fenómenos políticos y culturales emergentes de la Constitución de 1991 tampoco es única o necesaria en la consolidación organizativa en Guamal. Como se verá más adelante a través de los ejemplos etnográficos y jurídicos, las comunidades cuentan con un amplio conjunto de prácticas y discursos que están al servicio de la defensa de la identidad y del territorio, y en muchos casos no remiten necesariamente a los conceptos, normas y pautas que la ley ha definido con estos mismos fines.

No obstante es importante destacar que esta ley, junto con la normatividad subsiguiente que la complementa, marca el nacimiento de debates y disputas entre las mismas comunidades, en las que la identidad étnica, los derechos políticos y la propiedad sobre la tierra tomaron un lugar central. En este caso es válido afirmar que los elementos relativos a la legislación multicultural no solamente posibilitaron una reconfiguración de las relaciones entre las comunidades y el Estado (o los grupos mayoritarios), sino de las comunidades entre sí y, en el caso de Guamal, especialmente la relación entre los que podrían percibirse a priori como dos grupos étnicos claramente diferenciados, afros e indígenas. Esta afirmación podría llevarse más lejos al sostener que en general la aplicación del marco normativo multicultural también transformó las relaciones que hasta entonces habían 
tenido lugar entre los grupos étnicos y los grandes terratenientes, las empresas extractivas, los grupos armados o las redes clientelistas, por ejemplo.

Si se hace una lectura literal y plana de este panorama, se corre el riesgo de percibir el conjunto de movilizaciones organizativas y territoriales posteriores a la Constitución de 1991 como una respuesta mecánica a dicho marco normativo. Asimismo, tal interpretación tendería a traducir las diferencias étnicas del orden formal (en el marco de la ley) como diferencias efectivas en la realidad social. Esta precisión es especialmente pertinente en el caso de Guamal, al ser una localidad caracterizada por la diversidad cultural a lo largo de toda su historia; en consecuencia, no es posible afirmar de manera automática que los conflictos y disensos actuales entre las organizaciones sociales afros e indígenas puedan definirse necesariamente como la confrontación entre dos comunidades étnicas diferenciadas.

En el presente análisis, las relaciones interétnicas podrían definirse como intercambios simbólicos que tienen lugar entre grupos e individuos que defienden formas distintas de identidad étnica y que a la vez cohabitan en un mismo espacio geográfico. En este caso, los intercambios simbólicos en Guamal tienen lugar en la relación entre dos campos discursivos y prácticos diferentes (afro e indígena). Existiría así, siguiendo el argumento que Anne-Marie Losonczy (1997) desarrolló para las relaciones interétnicas que tienen lugar en el Chocó, una intersección donde se pueden aprehender las negociaciones, los consensos y los conflictos entre dos campos. No obstante, esta intersección hace al mismo tiempo parte constitutiva de cada uno de ellos.

El concepto de etnicidad que se defiende en el presente texto toma distancia de las perspectivas primordialistas (Río 2002; Wimmer 2008), en las que aquella aparece como una condición que los individuos portan, que es transmisible culturalmente y que es el resultado de diversos vínculos con el grupo social de referencia. Según Jean-François Gossiaux (1997), la crítica elaborada por Frederick Barth a los planteamientos primordialistas es interesante, en la medida en que propone invertir la perspectiva y no definir a priori los grupos étnicos como unidades culturalmente discretas. La etnicidad, estimaba Barth, no era una cuestión de cultura sino de organización social; así, analizar un grupo étnico de manera aislada no tendría sentido.

No obstante, en el marco de la lucha por la tierra a través de las políticas multiculturales, los elementos de la diferenciación étnica se vuelven, en ocasiones, más importantes que aquellos del intercambio. Las definiciones legales de los actores étnicos destacan la diferenciación cultural más que las intersecciones entre los grupos. Se puede decir que en Guamal hay una triangulación compleja 
que hay que aprehender; una convergencia no solo de los intereses de los colectivos indígenas frente a los afro, sino de estos grupos frente al Estado.

Dichos intereses pueden analizarse en el marco de las estrategias de apropiación territorial, entendido aquí como un diverso conjunto de herramientas que marcan un proceso social y cultural que objetiva la relación entre el ser humano y su hábitat, y que tiene como resultado la producción de territorio. La apropiación territorial es la manera en la que uno o varios agentes sociales se reservan, de manera individual o colectiva, la tierra, los recursos o el poder de decisión, a través de una o varias estrategias fundamentadas en formas distintas de autoridad. A continuación, mediante dos ejemplos etnográficos y jurídicos concretos, se intentará abordar algunas de las estrategias que se ponen en marcha en este contexto de relaciones interétnicas, que se insertan a su vez en un panorama más amplio de prácticas y discursos propios del multiculturalismo propuesto por el Estado.

\section{Sobre el reconocimiento del Consejo Comunitario Afrodescendiente de Guamal}

En Guamal convergen actualmente las autoridades del cabildo indígena de Cañamomo y Lomaprieta, las del Consejo Comunitario Afrodescendiente de Guamal y las del municipio de Supía. Los cabildos son organizaciones étnicas, políticas y territoriales que representan a las comunidades indígenas y son consideradas la máxima autoridad del gobierno propio, al hacer evidente su autonomía políticoterritorial frente al Estado. Por su parte, los consejos comunitarios son formas de organización interna propias de las comunidades negras, respaldadas especialmente por el marco normativo de la Ley 70 de 1993. Son organizaciones "encargadas de la defensa de los derechos de la propiedad colectiva, la preservación de la identidad cultural, el aprovechamiento y la conservación de los recursos naturales” (art. 5, Ley 70)5 . No obstante, los niveles de legitimidad, intervención,

5 Según el planteamiento de algunos autores frente a la constitución de ambas entidades, se podría afirmar que en Colombia se habría presentado un fenómeno denominado indianización de lo afro (Agier y Quintín 2004; Escobar 1997; Ng'weno 2013; Rivera 2004; Rossbach 2013; Wade 2013). El modelo indígena inspiró de manera importante una gran parte de los elementos jurídicos que reglamentaron la organización política y territorial afro en Colombia, luego de la Constitución Política de 1991. Su aplicación a los nacientes movimientos afros se hizo sin considerar necesariamente las diferencias esenciales existentes entre ambos grupos étnicos y sobre todo con respecto a la relación que establecerían con el Estado. 
representación y autoridad de estas organizaciones no son los mismos, y dicha convergencia está puesta en términos de una fuerte tensión y disenso. Antes de presentar el debate que se originó en el marco de la consolidación del Consejo Comunitario Afrodescendiente de Guamal, es importante señalar que los enfrentamientos entre las organizaciones indígenas y afros en este lugar tienen una larga historia, de la cual me interesa describir algunos elementos centrales para este análisis.

Actualmente comprendida por los municipios de Supía, Marmato y Riosucio en el departamento de Caldas, la región ha sido conocida desde el periodo colonial como de explotación minera. Durante la colonia convergieron fenómenos como la instalación de los amos de minas con las primeras cuadrillas de hombres y mujeres en situación de esclavitud, y la disminución de la población indígena local, resultado de las crudas condiciones de vida impuestas por la explotación del oro y de la plata (Colmenares 1973; Valencia 1994). En la transición hacia el periodo republicano a lo largo del siglo XIX, esta región estuvo fuertemente influenciada por la llegada de empresas mineras con capital inglés, al mismo tiempo que tomó fuerza la colonización antioqueña ${ }^{6}$ en las tierras fronterizas entre las regiones republicanas del Cauca y de Antioquia (Appelbaum 2007; González 1998). Este proceso estuvo vinculado a su vez con varios fenómenos concomitantes: la división de los resguardos indígenas (relacionada con la puesta en marcha de diferentes órdenes legislativos que buscaban ingresar las parcelas indígenas en un mercado de tierras más amplio), las guerras entre las regiones vecinas del Cauca y de Antioquia, la manumisión y liberación de los esclavos (1851-1852) y el fortalecimiento de un discurso liberal que buscaba crear una nación de ciudadanos (Muñoz 2015, 158).

Este momento histórico dio paso a la formalización y regularización de títulos de tierras que legitimaban la ocupación de los colonos antioqueños y caucanos, de los esclavos y sus descendientes, así como de los indígenas y de los demás pobladores de la zona durante la última mitad del siglo XIX y la primera del siglo XX. En este periodo tuvieron lugar diferentes disputas por la tierra en el contexto de formalización de la propiedad. Tras la transición republicana se generaron distintos tipos de normas y leyes que cambiaban frecuentemente de

Por esto, si bien ambas organizaciones étnicas tienen características muy distintas en contextos sociales disímiles, es posible encontrar entre ellas semejanzas estructurales en términos jurídicos y políticos.

6 Proceso de colonización interna emprendido por pobladores de la antigua región de Antioquia que tuvo su mayor auge a lo largo del siglo XIX. Las migraciones tuvieron como objetivo la instalación en regiones con menor presión demográfica y con mayores oportunidades para el desarrollo económico, ligado especialmente a la agricultura, a las actividades comerciales y en ocasiones a la minería. 
una región a otra, así como las divisiones político-administrativas del país durante estos años (González 1998). La región que abarca Supía y Riosucio, además de ser rica en minas y objeto de sucesivas concesiones de explotación minera, era una zona de frontera entre el Cauca y Antioquia, en la que la colonización y privatización de la tierra se dieron de manera particular, y provocaron diferentes tipos de conflictos con los resguardos indígenas y con los ocupantes de buena fe que allí se encontraban ${ }^{7}$. Este proceso favoreció el ingreso de las parcelas en un sistema de propiedad respaldado por diferentes mecanismos jurídicos, a través de los cuales las tierras se pudieron comprar y vender con mayor libertad. Como consecuencia de estas normas, en 1879 los representantes legales de la comunidad de Guamal y del cabildo de Supía y Cañamomo (actualmente Cañamomo y Lomaprieta) legitimaron (mediante el reconocimiento de propiedad particular, consignado en el folio de matrícula inmobiliaria número 115 registrado en la Oficina de Registro e Instrumentos Públicos de Riosucio) la ocupación territorial de los guamaleños y se comprometieron a respetar las normas de protección mutua y de común acuerdo entre las comunidades ${ }^{8}$. Sin embargo, las disputas y enfrentamientos por la propiedad y la legalidad de la ocupación de las tierras de Guamal se han mantenido hasta nuestros días, con picos de tensión en diferentes periodos de la historia local.

Las movilizaciones sociales campesinas e indígenas que tomaron fuerza desde los años setenta en Colombia lograron conformar una organización nacional y regional sólida a través de la cual indígenas y campesinos buscaron emprender una solicitud frente al Gobierno, con miras a defender el territorio y los derechos políticos de dichos pueblos. Esta movilización y el marco normativo de la Constitución de 1991 dieron como resultado, entre otras medidas de orden territorial y político, la recuperación de una gran parte de los títulos de propiedad perdidos por los indígenas en las épocas precedentes.

El reconocimiento constitucional logró consolidar los resguardos como entidades territoriales de propiedad colectiva dotadas de autonomía y regidas por las autoridades indígenas, que podrían hacer valer el derecho de ordenamiento territorial y de control de la vida interna del grupo en correspondencia con

7 Por esta y otras razones de la transición republicana es difícil definir qué tipo de títulos de propiedad tenían los habitantes de Guamal antes de 1891, dado que el mismo concepto de propiedad territorial en términos administrativos apenas se estaba forjando. La investigación de Gloria Lopera-Mesa (2010) en torno a los derechos sobre la tierra y las formas de propiedad actuales dentro del resguardo de Cañamomo y Lomaprieta esclarece la existencia de formas muy distintas de propiedad que generan ambigüedades y conflictos en el plano legal y social.

8 El documento se encuentra en el Archivo de la Comunidad de Guamal, con fecha del 28 de febrero de 1891, y fue transcrito parcialmente por Juan Pablo Yepes (2004). 
sus normas y tradiciones culturales. Siguiendo el argumento de Carlos Vladimir Zambrano citado por Gloria Lopera-Mesa (2010), estos territorios pueden considerarse como plurales, dado que "allí concurren una gran variedad de actores sociales que proponen proyectos de territorialidad y construcción de identidad diversos, en los cuales la regulación de los derechos sobre la tierra juega un papel crucial” (63). Como ejemplo, dentro del resguardo de Cañamomo y Lomaprieta, se pueden encontrar tierras con títulos notariales de particulares y títulos de antigua adquisición, entre otras formas de propiedad territorial que no son estrictamente comunales ni privadas (Lopera-Mesa 2010). No obstante, sus distintos propietarios debieron asumir aspectos relativos al derecho político indígena a partir de la reglamentación de los resguardos, consecuencia también de la entrada en vigor de la Constitución de $1991^{9}$. Por su parte, la localidad de Guamal quedó ubicada dentro de las tierras delimitadas por el resguardo indígena de Cañamomo y Lomaprieta, y el cabildo se declaró como una de las organizaciones sociales y políticas de los indígenas, como una de las instancias con derecho a ejercer control sobre el territorio de Guamal.

De este panorama interesa especialmente el enfrentamiento por el territorio y por los poderes comunales, tanto de quienes se identifican como afrodescendientes como de aquellos que se consideran indígenas ${ }^{10}$. Esto tras el reconocimiento de ambas comunidades como grupos étnicos con derechos especiales en el marco de la Constitución multicultural. Una parte de la población de Guamal afirma habitar sobre una porción de las tierras indígenas con todo el derecho a ocuparlas y a explotarlas; como residentes de una vereda del resguardo y al censarse ante el cabildo, adquieren derecho a los beneficios de las acciones afirmativas que el Estado confiere a las comunidades indígenas. Otra parte de los pobladores, especialmente aquellos que han liderado el movimiento

9 Una de las consecuencias de la reglamentación territorial de los resguardos, posterior a 1991, especialmente en Cañamomo y Lomaprieta, es el proceso de adjudicaciones a los comuneros, por parte del cabildo indígena, que consiste en que quienes cuenten con títulos privados dentro de la jurisdicción del resguardo los donen al cabildo para poder censarse como miembros de la comunidad. El cabildo les otorga un título de adjudicación que legitima el derecho de ocupación, pero los predios no pueden ser objeto de ninguna transacción (venta, alquiler, hipoteca, etc.) por parte de sus ocupantes sin previa autorización. En muchos casos las mejoras realizadas en dichos predios pueden ser objeto de transacciones, lo que genera ambigüedad en las formas de propiedad territorial dentro del resguardo. Además, siguen existiendo predios privados pertenecientes a personas que no se reivindican como indígenas, mas deben asumirse dentro de la jurisdicción del resguardo.

10 En esta región también se presentan distintos conflictos territoriales con pobladores que no reivindican ninguna identidad étnica en particular, como aquellos relacionados con la extracción minera a gran escala. Dichos conflictos no son objeto del presente análisis. 
afrodescendiente, afirman que la comunidad negra ${ }^{11}$ es la propietaria legítima de una parte de las tierras que corresponden actualmente al resguardo, y por lo tanto tienen total derecho de organizarse a través de la figura legal de consejo comunitario.

Pero el reconocimiento del Consejo Comunitario de Guamal se inscribe en la convergencia de diferentes escalas de administración territorial, y en este caso tuvo que ser reconocido en primer lugar por el municipio de Supía ${ }^{12}$ y posteriormente por el Ministerio del Interior ${ }^{13}$. No obstante, esta decisión no pasó inadvertida para el cabildo indígena, cuyo gobernador interpuso una acción de tutela ${ }^{14}$ en el año 2013 en contra del Ministerio del Interior y del municipio de Supía. La reclamación afirmaba que se había violado el derecho a la consulta previa de la comunidad indígena. El gobernador insistía en que, para proceder al reconocimiento del Consejo Comunitario de Comunidades Negras Afrodescendientes de Guamal, se habría tenido que consultar a la comunidad indígena, "pues se trata de una medida administrativa que afecta directamente la comunidad" (Corte Suprema de Justicia 2014, 3).

Según la legislación que reglamenta la conformación de los consejos comunitarios, especialmente la Ley 70 de 1993, estas entidades son definidas en su doble dimensión territorial y política ${ }^{15}$. Algunos autores definen la Ley 70 como étnico-territorial (Agier y Quintín 2004; Hoffmann 2004; Ruiz 2006), al mostrar que en ella se evoca, en ocasiones de manera explícita, la conocida ecuación: una etnia, un territorio, principio que orientaría sus políticas a partir de tal supuesto. La reclamación del gobernador del resguardo toma otro matiz al considerar que

11 Empleo el concepto de comunidad negra cuando entra en relación con las normativas que la definen como sujeto de derechos políticos y territoriales (Ley 70 de 1993 y debates subsiguientes).

12 Amparado en las siguientes normativas: artículo 315, numeral 1, de la Constitución; art. 91 de la Ley 1551 de 2012; Ley 70 de 1993 y Decreto 1745 de 1995.

Amparado además en el Decreto 2893 de 2011 y en el art. 15 del Decreto 3770 de 2008. La Dirección de Asuntos Indígenas, Rom y Minorías del Ministerio reglamenta asuntos relativos a los grupos étnicos en Colombia y reconoce formalmente a las organizaciones de base y consejos comunitarios de las comunidades negras.

El artículo 5 de la Ley 70 afirma que, "para recibir en propiedad colectiva las tierras adjudicables, cada comunidad formará un consejo comunitario como forma de administración interna, cuyos requisitos determinará el reglamento que expida el Gobierno nacional. Además de las que prevea el reglamento, son funciones de los consejos comunitarios: delimitar y asignar áreas al interior de las tierras adjudicadas; velar por la conservación y protección de los derechos de la propiedad colectiva, la preservación de la identidad cultural, el aprovechamiento y la conservación de los recursos naturales; escoger al representante legal de la respectiva comunidad en cuanto persona jurídica, y hacer de amigables componedores en los conflictos internos factibles de conciliación". 
efectivamente la emergencia de un consejo comunitario afro legalmente constituido representaría una amenaza para los intereses de su comunidad, en primer lugar en el plano de lo político, y posteriormente en el plano de las reclamaciones por la propiedad de la tierra.

Por su parte, en el mencionado fallo de la Corte, la respuesta del Ministerio del Interior deja ver la evidente confusión, que en términos institucionales y legales genera un contexto de relación interétnica como el de Guamal:

La directora de Asuntos para Comunidades Negras, Afrocolombianas, Raizales y Palenqueras del Ministerio del Interior precisó que no había vulnerado ningún derecho fundamental al libelista [el gobernador indígena] porque para la expedición de la Resolución n.$^{\circ} 083$ de julio 10 de 2013, por medio de la cual inscribió al Consejo de Comunidades Negras de Guamal en el Registro Nacional Único, no era necesario adelantar "proceso de consulta previa, por cuanto este procedimiento involucró asuntos internos de los miembros de una misma comunidad étnica, quienes de conformidad con sus usos y costumbres decidieron de manera autónoma iniciar el trámite como consejo comunitario; situación esta que no involucra afectación por parte de personas jurídicas o naturales ajenas al grupo étnico que ahora reclama la consulta previa”. (Corte Suprema de Justicia 2014, 4; énfasis en el original)

Desde la perspectiva analítica que el presente artículo intenta desarrollar, es importante destacar que en este hecho se ponen en marcha estrategias de apropiación territorial de carácter jurídico y que responden a un marco normativo claramente identificable. Las leyes y políticas diseñadas por el Estado son apropiadas por los agentes locales, en este caso el cabildo indígena y la naciente organización afro que buscan reclamar o defender lo que consideran como propio, en medio de la relación establecida con el Estado, que estaría habilitado para reconocer los derechos de unos y otros.

La relación interétnica complejiza la intervención de las instituciones estatales, en este caso la del Ministerio del Interior que debe hacer valer los derechos organizativos y de representación de los distintos grupos étnicos frente al Estado. La respuesta de la entidad pública deja ver una lectura primordialista de la etnicidad antes mencionada, para mostrar el carácter étnico-territorial de algunas de las medidas legislativas. La definición de comunidad o grupo étnico que el Ministerio del Interior presenta de manera implícita en el fragmento anterior hace pensar nuevamente en la dudosa correspondencia, abordada por Gupta 
y Ferguson (2008), entre una etnia y un territorio, cuando en este y en otros casos es difícil establecer los límites de los grupos en cuanto a su pertenencia étnica.

El fallo que la Corte Suprema de Justicia dio a la acción de tutela en cuestión no respondió a los asuntos de fondo de la reclamación. Se limitó a declarar extemporánea la impugnación interpuesta por el gobernador indígena al fallo de la Sala de Decisión Penal del Tribunal Superior de Manizales y se abstuvo de resolver el recurso, enviando el expediente a la Corte Constitucional para una eventual revisión del fallo de primera instancia. Entre tanto, la tensión entre los representantes del cabildo indígena y del consejo comunitario ha mostrado otros síntomas, sobre todo en discusiones y debates relativos a asuntos puntuales de la vida local, que se inscriben en lógicas mayores alusivas a las dinámicas políticas regionales e incluso nacionales. Algunos enfrentamientos han tenido que ver con el desarrollo de proyectos de infraestructura y servicios públicos, la elección de líderes políticos locales, la realización y organización de festividades, la distribución de recursos tanto del resguardo como de la municipalidad, entre otros.

Por su parte, los miembros del consejo comunitario afro, creado y respaldado por la resolución del Ministerio del Interior, han decidido continuar con el proceso de consolidación territorial de dicha organización, y amparados por el marco normativo de la Ley 70 han emprendido la reclamación de las tierras frente al Instituto Colombiano de Desarrollo Rural (Incoder) ${ }^{16}$. Es posible afirmar que esta reclamación moviliza una amplia gama de recursos y estrategias de apropiación territorial de orden jurídico, a través de los cuales se busca replantear la relación de autoridad y poder de decisión sobre una parte de las tierras del resguardo indígena; tierras que una parte de los habitantes de Guamal reclaman como propiedad de la comunidad guamaleña desde muchos años atrás.

\section{Un testamento y tres estrategias de apropiación territorial}

Declaro por bienes míos una cuadrilla compuesta por ciento setenta y cinco piezas de esclavos poco más o menos, entre hombres y mujeres, grandes y chicos, cuyo número resultará del inventario que se forme por familias y casas de ranchería en que habitan [...] es su voluntad que 
estos negros permanezcan indefinidamente en este mineral de Guamal, observando obediencia para con sus nuevos amos, al tiempo que dejen las normas necesarias para el buen gobierno de esta cuadrilla después de su muerte, haciendo a los esclavos algunas concesiones y otorgándoles privilegios. (Citado en Duque 1944, 645)

Este fragmento de un testamento "hace parte” de uno de los documentos más controvertidos y al mismo tiempo significativos de la historia de Guamal. En algunos relatos locales que me fueron compartidos durante mi trabajo de campo, y en otras referencias de distintos antropólogos e historiadores que han trabajado en la región (Appelbaum 2007; Duque Gómez 1944; Yepes 2004), el testamento de Josefa Moreno de la Cruz, antigua propietaria de esclavos de finales del siglo XVIII y principios del siglo XIX, marca el origen de Guamal como pueblo libre y heredero legítimo de las tierras que hoy la comunidad ocupa. Este documento ha servido como principio de una gran variedad de discursos fundacionales de la comunidad guamaleña.

El fragmento citado es una transcripción del testamento de Josefa Moreno, obtenida por el antropólogo Luis Duque Gómez durante su trabajo de campo en el departamento de Caldas en el año 1943. En un artículo publicado por el Instituto Nacional de Etnología en 1944, el autor afirma haberlo encontrado en los antiguos archivos notariales del municipio vecino de Riosucio. No obstante, estos archivos parecen haber sufrido graves daños durante la época de la Violencia política de los años cincuenta y la sección indicada por el autor habría sido quemada durante este periodo convulsionado. Una segunda referencia sobre el mismo documento fue encontrada en el Archivo del Juzgado del Circuito Civil de Riosucio. Nancy Appelbaum (2007) y Juan Pablo Yepes (2004) señalan que en dichos archivos reposa una solicitud interpuesta en 1878 por Pablo Vicente Moreno ante el administrador encargado de las tierras de Guamal, Francisco de Lemos, heredero directo de Josefa Moreno de la Cruz. En este documento aparecía la referencia explícita del testamento como prueba de la mentada demanda ${ }^{17}$.

[...] "nombro por mis únicos y universales herederos del remanente líquido de todos mis bienes, intereses derechos y futuras acciones presentes y futuras a la iglesia viceparroquia de $\mathrm{S}^{\mathrm{a}}$ Santana que me hallo construyendo en este Guamal; a mi sobrino consanguíneo e hijo adoptivo Pablo Vicente Moreno y a mi sobrino también consanguíneo Francisco Gervacio de Lémos. Advirtiendo que como por cláusula anterior de este mi testamento he dispuesto se conserven los esclavos de mi cuadrilla en labor de mona [mina] de oro corrido de Guamal, los tres primeros días de cada semana, deberá subsistir por demancomún entre los tres herederos el valor de los citados esclavos, mina y sus herramientas para que sus productos lo mismo que el valor de los esclavos que puedan libertarse por su dinero correspondan así mismo a todos tres por iguales partes destinando las de la capilla 
La existencia factual del testamento de Josefa Moreno de la Cruz ha sido fuertemente defendida por los representantes del Consejo Comunitario Afrodescendiente de Guamal, así como por una gran parte de los habitantes de la vereda, quienes reconocen los relatos sobre el testamento como parte esencial de la historia local. En el 2013, uno de los líderes de esta organización y para entonces concejal del municipio de Supía, William Moreno, insistía en que podría existir una copia del testamento en alguno de los archivos de la región.

A partir de los ejemplos citados, si bien el testamento reconoce que para la época estas tierras estaban ocupadas por un grupo importante de esclavos mineros, el documento no afirma en ninguna de las dos fuentes que las tierras les hayan sido heredadas directamente. No obstante, el testamento de Josefa Moreno, más que un documento de archivo, ha logrado perdurar más allá de lo que podrían considerarse como pruebas fácticas, a través de los discursos y prácticas, tanto cotidianas como rituales de la comunidad, y nos permite evidenciar otras formas de apropiación territorial distintas a las de orden jurídico que se pudieron presentar anteriormente.

La apropiación territorial en Guamal parece también depender de un conjunto de estrategias discursivas de un tipo particular, que buscan determinar la autoridad con respecto al territorio. Así, el testamento no existe solamente en el marco de la prueba sino más allá de ella como discurso fundacional apropiado y reproducido en el seno de la comunidad. Nuevamente el antropólogo Juan Pablo Yepes, durante la entrevista realizada a un docente de Guamal en el año 2004, nos da algunas pistas concernientes a la manera en que algunos guamaleños han logrado conservar el testamento mediante una gran variedad de discursos locales, entre los cuales el siguiente es revelador:

Ana Josefa Moreno era la dueña de una recua de esclavos, y era una terrateniente que nos defendió, y la herencia que ella tenía se la heredó a sus esclavos. Supuestamente tenía dos sobrinos, Francisco Lemos y Pablo Vicente. Ella repartió la tierra para ellos y nosotros, con la condición de trabajar las tierras de Santa Ana, o sea las tierras debíamos explotarlas para sostener la iglesia y la imagen de la santa. Inclusive se dice que los esclavos trajeron al hombro la imagen desde el Ecuador, a pie [...] No sé cómo pasó pero nosotros quedamos con las tierras, o por lo menos eso decía el testamento de la señora. Es que ella era benévola a diferencia de los otros amos, ella nos quería y quería que fuéramos libres [...] nos dejó lo principal para todos los guamaleños, el culto a Santa Ana que

a proveerla de lo que pueda necesitar" (Archivo del Juzgado del Circuito Civil de Riosucio,

3 de julio de 1878, ff. 14-17, citado en Yepes 2004, 30). 
es nuestra patrona, nuestra protectora y, por supuesto, todo su territorio [...] Mantener el legado de la señora Josefa es para nosotros una forma de defender nuestra fe... y las tierras. (Yepes 2004, 28)

Discursos como el anterior permiten introducir el hecho de que la herencia de Josefa Moreno no es solamente una cuestión de traspaso de tierras. En los relatos que recopilé en campo, así como en los referidos anteriormente, resultado de la investigación de Juan Pablo Yepes, el testamento de la antigua propietaria de esclavos está legando mucho más que el derecho de ocupación territorial.

El testamento, como discurso fundacional, pone en evidencia varias estrategias de apropiación territorial entre las que destacaré tres esenciales: estrategias relativas a la filiación o al parentesco (la herencia del apellido), estrategias mítico-religiosas (herencia del culto a Santa Ana) y estrategias de acción política (ruptura con la esclavitud o "libertad donada” por quien en sus relatos aparece como máxima benefactora y fundadora de la comunidad). Los diferentes elementos señalados como legado, recurrentes en los relatos sobre el testamento, pueden ser considerados como pilares de las dinámicas de reivindicación política y territorial de los guamaleños en diferentes momentos de la historia de la localidad, incluyendo el actual. Lo más interesante de estos elementos es que son esgrimidos en contextos diferentes y con propósitos muy variados.

El testamento soporta un amplio conjunto de prácticas, tanto rituales como cotidianas. Ejemplo de ellas son algunos eventos festivos, como el Carnaval Negroide de Guamal, que tiene lugar cada dos años; la fiesta de Santa Ana y la fiesta de Santa Lucía, celebradas anualmente, o las celebraciones cívicas. En estos eventos emerge una gran cantidad de discursos que refieren los principios fundacionales de la comunidad en búsqueda de la defensa del territorio y de una identidad guamaleña distinta a la de sus vecinos indígenas (Lara-Largo 2014).

Las referencias a la libertad, como un valor fundamental de la identidad guamaleña y como marcador del origen de la comunidad, son claramente resaltadas en el marco de los discursos festivos que tienen lugar en el Carnaval Negroide. En el año 2013 alguna de las cuadrillas del carnaval cantaba "la alegría de ser negros y de llevar en la piel el color de la libertad y el coraje”. Asimismo, sobre el enfrentamiento con el cabildo indígena de Cañamomo y Lomaprieta, durante una entrevista de campo en el año 2014, uno de los líderes del Consejo Comunitario Afrodescendiente señalaba: “¿Por qué es que siempre tenemos que pedirles permiso a los indios? Hasta para mover una silla hay que tener un permiso. Tenemos que recuperar nuestra autonomía y dirigir nuestro territorio, y tomar nuestras propias decisiones ¡Nosotros ya ganamos la libertad una vez!”. 
La libertad es entonces un marcador identitario importante, al igual que el hecho de tener el apellido Moreno. Ser Moreno implica la pertenencia a la comunidad y la defensa de un conjunto de ancestros comunes. Jorge Moreno, líder comunitario y operador de transporte público en Supía, afirmaba en alguno de nuestros diálogos en el año 2014 que, si bien él se consideraba "mitad guamaleño” porque su mamá era una mujer mestiza de Supía, su hija ahora era una "verdadera guamaleña", porque él y su esposa, también de Guamal, le habían heredado nuevamente el apellido Moreno Moreno. En este ejemplo, así como en algunos otros que pudieron ser referenciados a lo largo del trabajo de campo, en los que se expresa además una explícita regla endogámica (existente en el plano de la norma y no necesariamente en el campo de la práctica), aparece constantemente la defensa de la unidad comunitaria guamaleña. Algunos de los discursos intentan crear un vínculo entre las prácticas, los ancestros y los hitos del pasado, con las prácticas y discursos de defensa identitaria y territorial en el presente (Lara-Largo 2014).

En una entrevista periodística realizada al líder William Moreno, en el marco de la celebración del Día de la Afrocolombianidad el 21 de mayo de 2012, se observa la importancia que él le otorga al elemento del parentesco, al tiempo que en su discurso convergen las otras dos estrategias de apropiación territorial, que se fundamentan en los principios de libertad y filiación:

Guamal es un asentamiento afrodescendiente que data del 8 de agosto de 1749, cuando el teniente general español llamado Simón Pablo Moreno de la Cruz se asentó por acá entre Supía y Guamal con 25 esclavos y ganado [...] Ana Josefa Moreno fue quien nos dio el apellido, Moreno. Después de que nos liberó de la esclavitud, ella nos regaló las tierras que hoy estamos poblando y nos regaló el apellido Moreno, por eso hoy en Guamal, el $98 \%$ tenemos ese apellido. (Gobernación de Caldas 2012)

En esta narrativa, así como en las anteriores, los elementos de filiación, libertad y territorio están fuertemente imbricados y construyen un conjunto argumentativo que opera mediante relatos que reglamentan la práctica política y territorial del presente a través de un vínculo estricto con personas y eventos del pasado. En dos de los relatos anteriormente señalados, la dependencia de los guamaleños del resguardo indígena podría ser controvertida en nombre de la libertad obtenida ya una vez (la ruptura con la esclavitud), que es al mismo tiempo una característica de la identidad guamaleña (destacada en los cantos de las cuadrillas en el carnaval), y que manifiesta además una voluntad renovada de acción política autónoma. En este caso el concepto local de libertad (en complemento 
con la propiedad de la tierra y el ser Moreno) legitima la lucha por los derechos políticos y territoriales frente al resguardo indígena.

La diversidad de discursos y prácticas alrededor del legado de Josefa Moreno de la Cruz, así como su apropiación por parte de los habitantes de Guamal, a través de su memoria colectiva, nos permiten poner en evidencia distintas estrategias de apropiación territorial que no necesariamente son de orden jurídico. De hecho, las que hemos analizado posibilitan una nueva perspectiva frente al fenómeno de organización social y política que ha tenido lugar en esta localidad interétnica. Si bien la Constitución Política de 1991, así como la legislación relacionada, produjeron cambios importantes en la relación entre los grupos étnicos que cohabitan en esta y en otras regiones del país, no es posible afirmar que dichas transformaciones sean consecuencia exclusiva de este marco normativo.

En este caso, frente a la cuestión de las relaciones interétnicas en Guamal, es pertinente poner en marcha un modelo a múltiples escalas con el fin de comprender la emergencia de las fronteras étnicas. El modelo teórico elaborado por Andreas Wimmer (2008) parece conveniente en tanto permite analizar la configuración de los órdenes institucionales, de beneficios en el marco de las lógicas de poder y de la relación entre el consenso y la frontera. Considero que es útil en la explicación del funcionamiento de las formas distintas de construcción de la etnicidad como resultado de un círculo de reproducción y de transformación, que está compuesto por diferentes niveles de estabilización y de evaluaciones transformadoras. Todo esto en el marco de las estrategias de apropiación territorial que se configuran en un contexto amplio relacionado con el multiculturalismo de Estado, pero que no pueden reducirse a este.

\section{Conclusión}

En el presente análisis he buscado hacer evidente la complejidad de un contexto de relación interétnica en el que se ponen en juego dinámicas territoriales y políticas. En este contexto, el hecho de reivindicarse como indígena o afrodescendiente, es decir, defender una forma particular de etnicidad, implica la existencia de fronteras configuradas por órdenes institucionales y beneficios en el marco de las lógicas de poder. 
En los ejemplos presentados se hace evidente la dificultad jurídica y social de definir “quién es quién”, sobre todo cuando se plantean las disputas como conflictos entre dos etnias. Tal lectura de la etnicidad, por demás primordialista, hace pensar que los grupos étnicos son portadores de una identidad exclusiva, que los ubica a unos frente a otros como unidades discretas, algo que no ocurre en el caso de Guamal. Por otra parte, no es posible afirmar entonces que las prácticas de diferenciación étnica sean simples respuestas automáticas a la búsqueda de los beneficios que otorga la ley (lectura instrumentalista). En este caso, todo movimiento social sería desvirtuado en nombre del utilitarismo y se haría aparecer las reivindicaciones étnicas como un intento premeditado por coincidir con las formas ejemplares de la etnicidad estipuladas por la ley (Oslender 2002). Asimismo, generaría una falsa idea de causalidad entre las políticas multiculturales y las formas organizativas, políticas y étnicas de las comunidades. Como se pudo evidenciar a lo largo del texto, en Guamal, la idea de libertad, presente en el discurso fundacional, precede a la de autonomía, claramente instaurada por las políticas multiculturales. El ser Moreno o guamaleño, fundamento de la noción de comunidad, va más allá de ser indígena o afrodescendiente, categorías con un claro contenido político y agenciadas en el marco de la ley. Esto tampoco quiere decir que estas categorías se reduzcan a dichas instancias; por el contrario, tienen un papel fundamental en la producción y reproducción de prácticas y discursos en donde los límites y fronteras de la etnicidad configuran la organización étnico-política y la legitimación del territorio.

Las intervenciones del Estado han generado transformaciones en la manera en que se configuran las organizaciones étnico-políticas que representan los intereses de algunos fragmentos de la comunidad, y estas no deben ser vistas como la comunidad en su conjunto. Si en Guamal existe un conflicto entre los adherentes al consejo comunitario afrodescendiente y los miembros del cabildo indígena de Cañamomo y Lomaprieta, esto no quiere decir de manera automática que exista un conflicto interétnico, como lo refieren en ocasiones los medios y, lo que es más preocupante, las mismas instituciones del Estado. Es más bien un conflicto en el que la etnicidad está en el centro de las relaciones de poder, de autoridad y de territorialidad. Y, efectivamente, los individuos y las colectividades toman partido y construyen sus prácticas cotidianas y rituales en el marco de estas complejas dinámicas al poner en marcha diversas estrategias de apropiación territorial. 


\section{Referencias}

Agier, Michel y Pedro Quintín. 2004.

"Política, cultura y autopercepción: las identidades en cuestión.” En Gente negra en Colombia. Dinámicas sociopolíticas en Cali y el Pacífico, editado por Olivier Barbary y Fernando Urrea, 397-413. Medellín: Lealon; Cidse, Universidad del Valle; IRD; Colciencias.

Agudelo, Carlos. 2004. Politique et populations noires en Colombie: enjeux du multiculturalisme. París: L'Harmattan.

Agudelo, Carlos, Odile Hoffmann y Nelly Rivas. 1999. Hacer política en el Pacífico sur: algunas aproximaciones. Documento de trabajo n. ${ }^{\circ}$ 39. Cali: Cidse, Universidad del Valle, Facultad de Ciencias Sociales y Económicas.

Appelbaum, Nancy. 2007. Dos plazas una nación: raza y colonización en Riosucio, Caldas, 1846-1948. Bogotá: Universidad de los Andes.

Arocha, Jaime, comp. 2004. Utopía para los excluidos. El multiculturalismo en África y América Latina. Bogotá: CES, Facultad de Ciencias Humanas, Universidad Nacional.

\section{Barbary, Olivier y Fernando Urrea,} comps. 2004. Gente negra en Colombia. Dinámicas sociopolíticas en Cali y el Pacífico. Medellín: Lealon; Cidse, Universidad del Valle; IRD; Colciencias.

Colmenares, Germán. 1973. Historia económica y social de Colombia, 1537-1719. Bogotá: Universidad del Valle, División Humanidades.

Congreso de Colombia. Ley 70 de 1993. Por la cual se desarrolla el artículo transitorio 55 de la Constitución Política.

Corte Suprema de Justicia. 2014. Fallo ATP020-2014-2014. Bogotá, Sala de
Casación Penal, Sala de Decisión de Tutelas n. ${ }^{2}$-CSJ.

Cunin, Elisabeth. 2004. Métissage et multiculturalisme en Colombie (Carthagène) Le "noir" entre apparences et appartenances. París: L'Harmattan.

Di Meo, Guy. 1998. Géographie sociale et territoires. París: Nathan.

Duque Gómez, Luis. 1944. "Informe de la visita antropológica realizada en 1943 al departamento del Viejo Caldas, con especial referencia a los indígenas del río $\mathrm{La}$ Vieja (Quindío), Riosucio y Supía (Caldas) y Quinchía (Risaralda), además de la comunidad negra de Guamal (Supía, Caldas)". Revista del Instituto Etnológico Nacional 2: 645-677.

Escobar, Arturo. 1997. "Política cultural y biodiversidad: Estado, capital y movimientos sociales en el Pacífico colombiano”. En Antropología de la modernidad: indentidades, etnicidades y movimientos sociales en Colombia, editado por María Victoria Uribe y Eduardo Restrepo, 173-206. Bogotá: ICANH.

Gobernación de Caldas. 2012. "Entrevista a William de Jesús Moreno Hernández, habitante de Guamal”. Consultado el 13 de abril del 2015. https://soundcloud. com/gobernaci-n-de-caldas/william-dejes-s-moreno-hern.

González Escobar, Luis Fernando. 1998. “Ocupación, poblamiento y territorialidades en la Vega de Supía, 1810-1950”. Tesis de Maestría en Estudios Urbano Regionales, Universidad Nacional de Colombia, sede Medellín.

Gossiaux, Jean-François. 1997. "Ethnicité, nationalités, nation”. En Anthropologie du politique, editado por Marc Abeles y Henri-Pierre Jeudy, 27-40. París: Armand Colin.

Gupta, Akhil y James Ferguson. 2008. “Más allá de la ‘cultura’: espacio, 
identidad y las políticas de la diferencia”. Antípoda 7: 233-256.

Hoffmann, Odile. 2004. Communautés noires dans le Pacifique colombien: innovations et dynamiques ethniques. París: Karthala.

Lara-Largo, Sofía. 2014. "Fêtes populaires, organisation politique locale et conflits territoriaux dans le Caldas-Colombie”. Tesis de maestría, École de Hautes Études en Sciences Sociales (Ehess).

Lopera-Mesa, Gloria. 2010. “Territorios, identidades y jurisdicciones en disputa: la regulación de los derechos sobre la tierra en el resguardo CañamomoLomaprieta”. Universitas Humanística 69: 61-81.

Losonczy, Anne-Marie. 1997. Les saints et la forêt. Rituel, société et figures de l'échange entre noirs et indiens emberá (Chocó, Colombie). París: L’Harmattan.

Muñoz, Fernanda. 2015. "De tierras de resguardo, solicitudes y querellas: participación política de indígenas caucanos en la construcción estatal (1850-1885)". Historia Crítica 55: 153-177.

Ng'weno, Bettina. 2013. “¿Puede la etnicidad reemplazar lo racial? Afrocolombianos, indigenidad y el Estado multicultural en Colombia”. Revista Colombiana de Antropología 49 (1): 71-104.

Oslender, Ulrich. 2002. The Logic of the River: A Spatial Approach to Ethnic Territorial Mobilization in the Colombian Pacific Region. Glasgow: Department of Geography University of Glasgow.

Otero, Natalia. 1994. "Los hermanos espirituales. Compadrazgo entre pobladores afrocolombianos e indígenas embera en el río Amporá (alto Baudó-Chocó)”. Tesis de pregrado en Antropología, Universidad de los Andes, Bogotá.

Pacheco, Esperanza y Alberto Achito. 1993. "Relaciones interétnicas en el Chocó hoy”. En Contribución africana a la cultura de las Américas, editado por Astrid Ulloa, 217-224. Bogotá: ICANH; Biopacífico.

Pardo, Mauricio. 1996. "Movimientos sociales y relaciones interétnicas”. En Pacífico: ¿desarrollo o diversidad? Estado, capital y movimientos sociales en el Pacífico colombiano, editado por Arturo Escobar y Álvaro Pedrosa, 299-315. Bogotá: Cerec.

Raffestin, Claude. 1980. Pour une géographie du pouvoir. París: Litec.

Restrepo, Eduardo, comp. 2013. Estudios afrocolombianos hoy. Aportes a un campo transdisciplinario. Popayán: Universidad del Cauca.

Rivera, Camila. 2004. "Nuevas encrucijadas, nuevos retos para la construcción de la nación pluriétnica: el caso de Providencia y Santa Catalina”. En Conflicto e (in)visibilidad: retos de los estudios de la gente negra en Colombia, editado por Axel Rojas y Eduardo Restrepo, 301-330. Popayán: Universidad del Cauca.

Rodríguez, Stella. 2002a. "Libres y culimochos: ritmo y convivencia en el Pacífico sur colombiano”. En Afrodescendientes en las Américas: trayectorias sociales e identitarias, editado por Claudia Mosquera, Mauricio Pardo y Odile Hoffmann, 313-332. Bogotá: Universidad Nacional de Colombia; ICANH; IRD; ILSA.

-. 2002b. "Poblaciones blancas en el Pacífico: historia y vigencia”. Maguaré 15-16: 114-135.

-. 2008. "Fronteras fijas, valor de cambio y cultivos ilícitos en el Pacífico caucano de Colombia”. Revista Colombiana de Antropología 44 (1): 41-70.

Río Ruiz, Manuel Ángel. 2002. "Visiones de la etnicidad". Revista Española de Investigaciones Sociológicas 98: 79-106.

Rossbach de Olmos, Lioba. 2013. "Dinámicas controvertidas: entre expresión étnica-cultural y la articulación política”. 
En Estudios afrocolombianos hoy: aportes a un campo interdisciplinario, editado por Eduardo Restrepo, 65-85. Popayán: Universidad del Cauca.

Ruiz, Daniel. 2006. Nuevas formas de ser negro. Consideraciones sobre las identidades entre la gente chilapa y negra del bajo Atrato. Colección Monografías. Caracas: Universidad Central de Venezuela.

Valencia Llano, Albeiro. 1994. Colonización, fundaciones y conflictos agrarios (Gran Caldas y norte del Valle). Manizales: Imprenta Departamental de Caldas.
Wade, Peter. 2013. "Definiendo la negridad en Colombia”. En Estudios afrocolombianos hoy: aportes a un campo interdisciplinario, editado por Eduardo Restrepo, 21-43. Popayán: Universidad del Cauca.

Wimmer, Andreas. 2008. "The Making and Unmaking of Ethnic Boundaries: A Multilevel Process Theory". American Journal of Sociology 113 (4): 970-1022.

Yepes, Juan Pablo. 2004. "Historia del conflicto en Guamal, Supía.” Tesis de grado en Antropología, Universidad de Caldas, Manizales. 